terone used in the common combined oral contraceptive preparations estimated over a 28-day cycle.

Obese middle-aged women appear prone to develop this rare condition, ${ }^{4}$ and this risk would appear compounded by prolonged hormone replacement treatment, as in this case. Careful repeated fundoscopic examination is thus mandatory in evaluating persistent headaches in patients taking hormone replacement treatment, as delayed diagnosis and treatment may result in long-term visual impairment. ${ }^{5}$

Both the manufacturers of Menophase, Syntex Pharmaceuticals Limited, and the National Drugs Advisory Board in Dublin have been informed about the case. The latter body communicates with the Committee on Safety of Medicines and the World Health Organisation, who state that they have no record of similar cases.

1 Horsman A, Gallagher JC, Simpson M, Nordin BEC. Prospective trial of oestrogen and calcium in postmenopausal women. Br Med $\mathcal{f} 1977$;ii 789-92.

2 Salmon ML, Winkleman JZ, Gay AJ. Neuro-ophthalmic sequelae in users of oral contraceptives. $\mathcal{F} A M A$ 1968;206:85-91.

${ }^{3}$ Walsh FB, Clark DB, Thompson RS, et al. Oral contraceptives and neuroophthalmologic interest. Arch Ophthalmol 1965;74:628-40.

Walton JN, ed. Brain's diseases of the nervous system. 8th ed. Oxford: Oxford Medical Publications, 1977:227.

5 Boddie HG, Banna M, Bradley WG. Benign intracranial hypertension. Brain 1974;97:313-26.

(Accepted 15 March 1982)

Department of General Medicine, Royal City of Dublin Hospital, Dublin 4

JOHN P SHEEHAN, MB, MRCPI, registrar

\section{Zinc deficiency due to alcoholic cirrhosis mimicking acrodermatitis enteropathica}

Zinc deficiency has been established as the cause of acrodermatitis enteropathica, an autosomal recessive disorder of zinc metabolism. The clinical features of acrodermatitis enteropathica may also be seen in acquired disorders of zinc deficiency. We describe a patient in whom the cause of zinc deficiency was alcoholic cirrhosis and malnutrition.

\section{Case report}

A 33-year-old woman was admitted to hospital in March 1981 with a history of loss of appetite, abdominal pain, and swelling. On examination she was thin and emaciated and showed signs of liver disease with jaundice, spider naevi, hepatomegaly, ascites, and oedema of the legs. She was evasive about her alcohol intake, but her family confirmed that she had been a heavy drinker, particularly during the past two years. Alcoholic liver disease was diagnosed. After admission she had episodes of gastrointestinal bleeding due to oesophageal varices, which were shown at endoscopy. Initial treatment included a low-sodium, low-protein diet and oral neomycin, lactulose, and diuretics. She required blood transfusion on three occasions.

By May tests of liver function showed improvement but she remained emaciated and malnourished, weighing $35 \mathrm{~kg}$. Parenteral feeding was attempted but was abandoned after nine days as she removed the subclavian line. Nasogastric feeding was not tolerated because of discomfort due to the nasogastric tube. She continued to be fed by mouth with supplements of folate and vitamins. Her general condition showed slow improvement, but she remained anorexic and suffered repeated episodes of nausea and vomiting and her weight did not increase above $38 \mathrm{~kg}$.

In July she developed typical lesions of acrodermatitis enteropathica around the nose, the angles of the mouth (figure), and in the perineum. There was a similar eruption over the elbows, knees, and dorsal aspect of the fingers.

Zinc deficiency was considered to be likely. Serum zinc concentration was $9 \cdot 0 \mu \mathrm{mol} / \mathrm{l}(58 \cdot 8 \mu \mathrm{g} / 100 \mathrm{ml})($ normal $12 \cdot 7-20 \cdot 2 \mu \mathrm{mol} / 1(83-132 \mu \mathrm{g} / 100 \mathrm{ml})$ ) and plasma albumin concentration was $26 \mathrm{~g} / 1$ (normal 30-50 g/1). Treatment was started with zinc sulphate $220 \mathrm{mg}$ thrice daily by mouth, and within one week the eruption had disappeared. In addition a sacral pressure sore that had been present before the onset of the rash started to heal. She died suddenly in August. At necropsy the cause of death was shown to be micronodular cirrhosis of the liver.

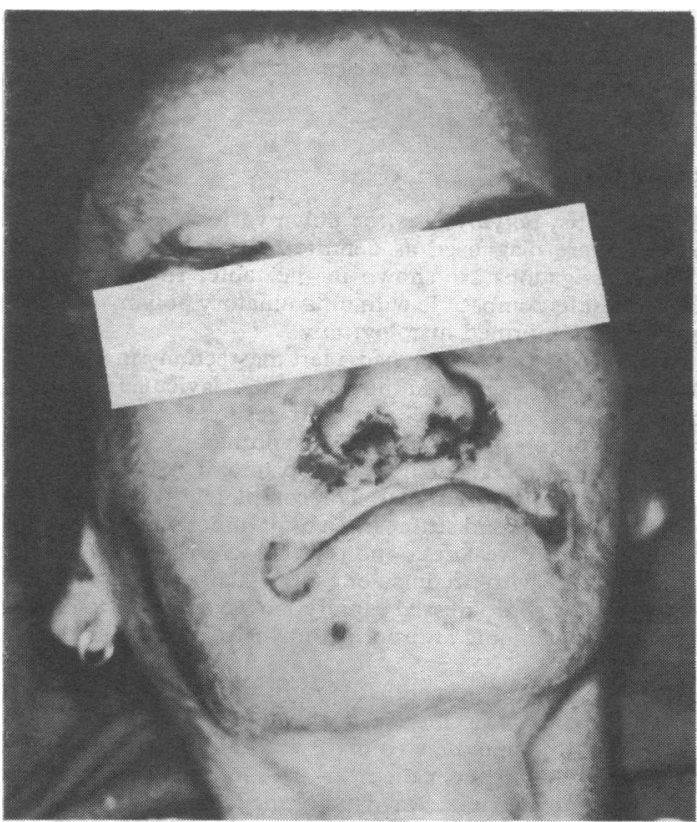

Erosive, erythematous eruption around nose and at angles of mouth before treatment.

\section{Comment}

An abnormality of zinc metabolism in alcoholic liver disease was first reported in 1957. ${ }^{1}$ The mechanism is unknown. Hyperzincuria is reported as a constant feature in hepatic cirrhosis but is not thought to be the cause of low plasma zinc concentrations. ${ }^{2}$ Low plasma zinc concentrations in cirrhosis may reflect the low plasma concentrations of albumin or other zinc-binding proteins. A true decreased zinc content in hepatic tissue has, however, been shown in patients with alcoholic liver diseases. ${ }^{3}$

Poor nutrition may contribute to zinc deficiency in alcoholics, and spirits and beer have a low zinc content. Malnutrition was certainly a factor in our patient. Long-term diuretic treatment causes increased urinary zinc excretion ${ }^{4}$ and in this case may have been a contributory factor.

The skin features of zinc deficiency were pronounced in our patient, the well-demarcated, erosive, erythematous eruption of the face, perineum, and extensor surfaces of the limbs and fingers being characteristic. Other cutaneous features of zinc deficiency that may occur include asteatotic eczema, alopecia, thin lustreless hair, nail dys trophy, and chronic paronychia. ${ }^{5}$

A single measurement of plasma or serum zinc concentration is not a good indicator of total body zinc stores. This patient's response to treatment, however, suggests that she indeed had acute zinc deficiency. This case appears to support the view that the best indicator of zinc deficiency is the response to treatment.

We thank Dr I Gilmore for permission to report this case, and Dr J L Verbov for his advice on the manuscript.

1 Vallee BL, Wacker WEC, Bartholomay AF, Hoch FL. Zinc metabolism in hepatic dysfunction. II Correlation of metabolic patterns with biochemical findings. $N$ Engl f Med 1957;257:1055-65.

${ }^{2}$ Walker BE, Dawson JB, Kelleher J, Losowsky MS. Plasma and urinary zinc in patients with malabsorption syndromes or hepatic cirrhosis. Gut 1973;14:943-8.

3 Kiilerich S, Dietrichson O, Loud FB, et al. Zinc depletion in alcoholic liver diseases. Scand $\mathcal{F}$ Gastroenterol 1980;15:363-7.

4 Wester PO. Zinc during diuretic therapy. Lancet 1975;i:578.

5 Weismann K, Wadskov S, Mikkelsen HI, Knudsen L, Christiansen KC, Storgaard L. Acquired zinc deficiency dermatosis in man. Arch Dermatol $1978 ; 114: 1509-11$

(Accepted 5 March 1982)

Department of Dermatology, Royal Liverpool Hospital, Liverpoo L7 8XP

A ILCHYSHYN, MB, MRCP, registra

$S$ MENDELSOHN, MB, MRCP, senior registrar 